University of South Florida

DIGITAL COMMONS

Digital Commons @ University of

@ UNIVERSITY OF SOUTH FLORIDA

South Florida

$12-3-2010$

\title{
Coupling of Surge and Waves for an Ivan-like Hurricane Impacting the Tampa Bay, Florida Region
}

\author{
Yong Huang \\ University of South Florida St. Petersburg \\ Robert $\mathrm{H}$. Weisberg \\ University of South Florida St. Petersburg, weisberg@usf.edu \\ Lianyuan Zheng \\ University of South Florida St. Petersburg
}

Follow this and additional works at: https://digitalcommons.usf.edu/msc_facpub

\section{Scholar Commons Citation}

Huang, Yong; Weisberg, Robert H.; and Zheng, Lianyuan, "Coupling of Surge and Waves for an Ivan-like Hurricane Impacting the Tampa Bay, Florida Region" (2010). Marine Science Faculty Publications. 173. https://digitalcommons.usf.edu/msc_facpub/173

This Article is brought to you for free and open access by the College of Marine Science at Digital Commons @ University of South Florida. It has been accepted for inclusion in Marine Science Faculty Publications by an authorized administrator of Digital Commons @ University of South Florida. For more information, please contact digitalcommons@usf.edu. 


\title{
Coupling of surge and waves for an Ivan-like hurricane impacting the Tampa Bay, Florida region
}

\author{
Yong Huang, ${ }^{1}$ Robert H. Weisberg, ${ }^{1}$ and Lianyuan Zheng $^{1}$ \\ Received 31 December 2009; revised 2 September 2010; accepted 8 September 2010; published 3 December 2010. \\ [1] The interactions between waves and storm surge are investigated using an \\ unstructured grid, coupled wave-surge model forced by a hypothetical Ivan-like hurricane \\ impacting the Tampa Bay, Florida region. The waves derived from the unstructured \\ version of the third-generation wave model simulating waves nearshore. The surge \\ derives from the unstructured Finite-Volume Coastal Ocean Model, to which \\ wave-induced forces (based on radiation stress theory) are added to the traditional \\ forces by winds and atmospheric pressure. Dependent upon complex bathymetry and \\ geometry, the wave-induced forces result in an additional $0.3 \sim 0.5 \mathrm{~m}$ of surge relative to \\ an uncoupled, surge-only simulation, and the increase in coastal sea level by the storm \\ surge adds some $1.0 \sim 1.5 \mathrm{~m}$ to the significant wave heights nearshore. Such strong \\ interactions through coupling suggest that waves should not be omitted in hurricane \\ storm surge simulations, especially because the forces by waves on coastal structures \\ are perhaps the most damaging of the hurricane related forces.
}

Citation: Huang, Y., R. H. Weisberg, and L. Zheng (2010), Coupling of surge and waves for an Ivan-like hurricane impacting the Tampa Bay, Florida region, J. Geophys. Res., 115, C12009, doi:10.1029/2009JC006090.

\section{Introduction}

[2] The potential for the transfer of momentum from the surface gravity waves to the underlying ocean currents is elucidated by Longuet-Higgins and Stewart [1964], Phillips [1977], and others. Such momentum transfers have prompted interest in its simulation using numerical models [e.g., Bowen et al., 1968; Mastenbroek et al., 1993; Xie et al., 2003; Mellor et al., 2008]. Moreover, after two successively active hurricane years, with Charley, Frances, Ivan, and Jeanne in 2004 followed by Dennis, Katrina, Rita, and Wilma in 2005, the public is now sensitized to the destructive effects of waves as hurricane-induced storm surge elevates the surf zone to residential neighborhoods [e.g., Sallenger et al., 2006]. This adds importance to the goal of enhancing the predictive capabilities by hurricane storm surge models used either for emergency preparedness, e.g., SLOSH (sea, lake, and overland surges from hurricanes) by NOAA [Jelesnianski et al., 1992] or for flood insurance rate maps, e.g., Advanced Circulation Multi-dimensional Hydrodynamic Model (ADCIRC) by Federal Emergency Management Agency (FEMA) [Westerink and Luettich, 1991], through the inclusion of waves. These extant storm surge models differ in their treatments of momentum flux either directly from the wind to the ocean currents or indirectly through the waves. Direct wind to currents momentum flux is based on bulk formulae for wind stress proportional to the square of the wind speed [e.g., Large and Pond, 1981]. Indirect

\footnotetext{
${ }^{1}$ College of Marine Science, University of South Florida, St. Petersburg, Florida, USA.

Copyright 2010 by the American Geophysical Union. 0148-0227/10/2009JC006090
}

transfer through waves is based on wave radiation stress theory [Longuet-Higgins and Stewart, 1964]. Both approaches are necessarily pragmatic ones, recognizing that the problem is more complex, entailing (1) the partition of wind and pressure work on the sea surface into waves and currents, (2) the mechanisms of transfer between the waves and currents, and (3) the resultant feedbacks between the waves and currents and within the wavefield itself. Ultimately, the performance of hurricane storm surge and wave models will depend on improved understandings of these complex physical processes. For now, we are limited to certain expediencies, which nevertheless are illuminating.

[3] Radiation stress theory [Longuet-Higgins and Stewart, 1964] provides an analytical means for imposing waveinduced forces on currents through the gradient of the radiation stress (e.g., as applied to ADCIRC by Luettich and Westerink [1999]). By coupling a wave model with a circulation model through radiation stress-induced forces, we can examine the contributions of the waves to the storm surge and the increased water elevation by storm surge to the waves. Such coupling suggests that these mutual influences should be most important in shoaling water where the surge height will be elevated by the wave-induced forces and where incremental changes in water level by storm surge will greatly impact the wavefield. Because regions of shoaling water are generally characterized by complex geometry, the use of unstructured grids is beneficial for resolving the associated fine-scale structures.

[4] The present application extends the study of Weisberg and Zheng [2008], which demonstrated the importance of three-dimensionality (3-D) in a hypothetical simulation of storm surge for Tampa Bay using Hurricane Ivan forcing but with landfall in the region of Tampa Bay, versus Pensacola, 
FL. Here we add the wave-induced forces by radiation stress. Section 2 describes the derivation of wave-induced forces and the coupled, storm surge and wave model configuration. Section 3 illustrates the new simulation of this Ivan-like hurricane landfall, compares the storm surge with and without wave coupling, and describes the evolution of the waves themselves with and without the effects of storm surge. A discussion and a summary are provided in section 4 .

\section{Coupled Model Description}

\subsection{Wave Radiation Stress and Wave-Induced Forces}

[5] Using small amplitude wave theory, the radiation stress is defined as the momentum flux due to the presence of waves [Longuet-Higgins and Stewart, 1964; Phillips, 1977] calculated by averaging, over a wave period, the vertically integrated flux of horizontal momentum in a field of waves, plus background currents, minus the flux in the absence of waves. For example, monochromatic waves propagating along the $x$ axis have a principle component of radiation stress given by

$$
\begin{aligned}
S_{x x} & =\frac{1}{T} \int_{0}^{T} \int_{-h}^{\eta}\left(\rho u^{2}+p\right) \mathrm{d} z \mathrm{~d} t-\int_{-h}^{0}(-\rho g z) \mathrm{d} z \\
& =\int_{-h}^{\eta}\left(\rho u^{2}+p\right) \mathrm{d} z-\frac{1}{2} \rho g h^{2}=E_{\mathrm{w}}\left(2 n-\frac{1}{2}\right),
\end{aligned}
$$

where $T$ is the wave period, $\eta$ is the wave displacement with respect to mean water level $z=0, h$ is the water depth with respect to mean sea level, $p$ is the pressure, $\rho$ is the water density, $g$ is the gravitational acceleration, and $E_{\mathrm{w}}$ is the wave energy density correct to second order in wave slope, $a k$, where $a$ is the wave amplitude and $k$ is the wave number, and $n=\frac{1}{2}\left(1+\frac{2 k h}{\sinh 2 k h}\right)$ is the ratio of the group to phase speeds.

[6] With the radiation stress proportional to the wave energy density, it is straightforward to derive it in spectral wave models, such as simulating waves nearshore (SWAN), wherein the radiation stress tensor becomes

$$
\begin{gathered}
S=\left[\begin{array}{ll}
S_{x x} & S_{x y} \\
S_{y x} & S_{y y}
\end{array}\right] \\
S_{x x}=\rho g \int\left[n \cos ^{2} \theta+n-\frac{1}{2}\right] E(\omega, \theta) \mathrm{d} \omega \mathrm{d} \theta \\
S_{x y}=S_{y x}=\rho g \int n \sin \theta \cos \theta E(\omega, \theta) \mathrm{d} \omega \mathrm{d} \theta \\
S_{y y}=\rho g \int\left[n \sin ^{2} \theta+n-\frac{1}{2}\right] E(\omega, \theta) \mathrm{d} \omega \mathrm{d} \theta,
\end{gathered}
$$

where $\mathrm{E}(\omega, \theta)$ is the directional wave energy density spectrum, $\omega$ is the absolute frequency determined by the Doppler shifted dispersion relation, and $\theta$ is the spectral direction.

[7] The relationship between wave radiation stress and wave energy density is clarified through the wave energy equation for the case of deepwater wave propagation in the absence of an underlying current. Here the local rate of change of wave momentum $(E / c$, where $c$ is the phase speed) is balanced by the spatial gradient in radiation stress $\left[\frac{\partial E / c}{\partial t}=-\frac{\partial S x x}{\partial x}\right]$ [e.g., Phillips, 1977, p. 70] from which we see that the gradient in radiation stress provides a force per unit area that balances the local rate of change of wave momentum per unit area. Thus, the components of the forces per unit area that are imposed by the waves on the fluid in the more general sense are

$$
\begin{aligned}
& F_{x}=-\left(\frac{\partial S_{x x}}{\partial x}+\frac{\partial S_{x y}}{\partial y}\right) \\
& F_{y}=-\left(\frac{\partial S_{y x}}{\partial x}+\frac{\partial S_{y y}}{\partial y}\right) .
\end{aligned}
$$

These wave-induced forces per unit area are added into the momentum equation of a circulation model to establish a wave and storm surge-coupled model.

\subsection{Wave-Induced Forces for a 3-D Circulation Model}

[8] The application of wave radiation stress in a 2-D circulation model is discussed by Luettich and Westerink [1999]. The vertical integration makes this fairly straightforward in that the wave radiation stress gradient provides a surface stress that is additive to the wind stress. Coupling waves to a 3-D circulation model requires an additional assumption on how the wave radiation stress is distributed over the water column. Here we employ the expediency of assuming that only in shallow water will the wave radiation stress provide a significant contribution to the height of the storm surge. Being that the wave pressure and horizontal velocity variations are uniformly distributed over the water column for shallow water waves, we assume a linear distribution for the wave radiation stress with depth, thereby providing for a depth uniform body force (depth uniform vertical gradient) by the wave radiation stress. Given this shallow water assumption, our application of wave radiation stress is the same as applied in the 2-D case by Luettich and Westerink [1999].

[9] With Boussinesq and hydrostatic approximations, the primitive momentum equations (with continuity included) for the circulation model inclusive of the wave-induced forces are

$$
\begin{gathered}
\frac{\partial(D u)}{\partial t}+\frac{\partial\left(D u^{2}\right)}{\partial x}+\frac{\partial(D u v)}{\partial y}+\frac{\partial(u \omega)}{\partial \sigma}-f D v \\
=-g D \frac{\partial\left(\eta-\eta_{a}\right)}{\partial x}-\frac{g D^{2}}{\rho_{0}} \int_{\sigma}^{0}\left[\frac{\partial \rho}{\partial x}-\frac{\sigma}{D} \frac{\partial D}{\partial x} \frac{\partial \rho}{\partial \sigma}\right] \\
\cdot d \sigma+\frac{\partial}{\partial \sigma}\left[\frac{K_{m}}{D} \frac{\partial u}{\partial \sigma}\right]+F_{u}+\frac{F_{x}}{\rho_{0}} \\
\frac{\partial(D v)}{\partial t}+\frac{\partial(D u v)}{\partial x}+\frac{\partial\left(D v^{2}\right)}{\partial y}+\frac{\partial(v \omega)}{\partial \sigma}+f D u \\
=-g D \frac{\partial\left(\eta-\eta_{a}\right)}{\partial y}-\frac{g D^{2}}{\rho_{0}} \int_{\sigma}^{0}\left[\frac{\partial \rho}{\partial y}-\frac{\sigma}{D} \frac{\partial D}{\partial y} \frac{\partial \rho}{\partial \sigma}\right], \\
\cdot d \sigma+\frac{\partial}{\partial \sigma}\left[\frac{K_{m}}{D} \frac{\partial v}{\partial \sigma}\right]+F_{v}+\frac{F_{y}}{\rho_{0}}
\end{gathered}
$$




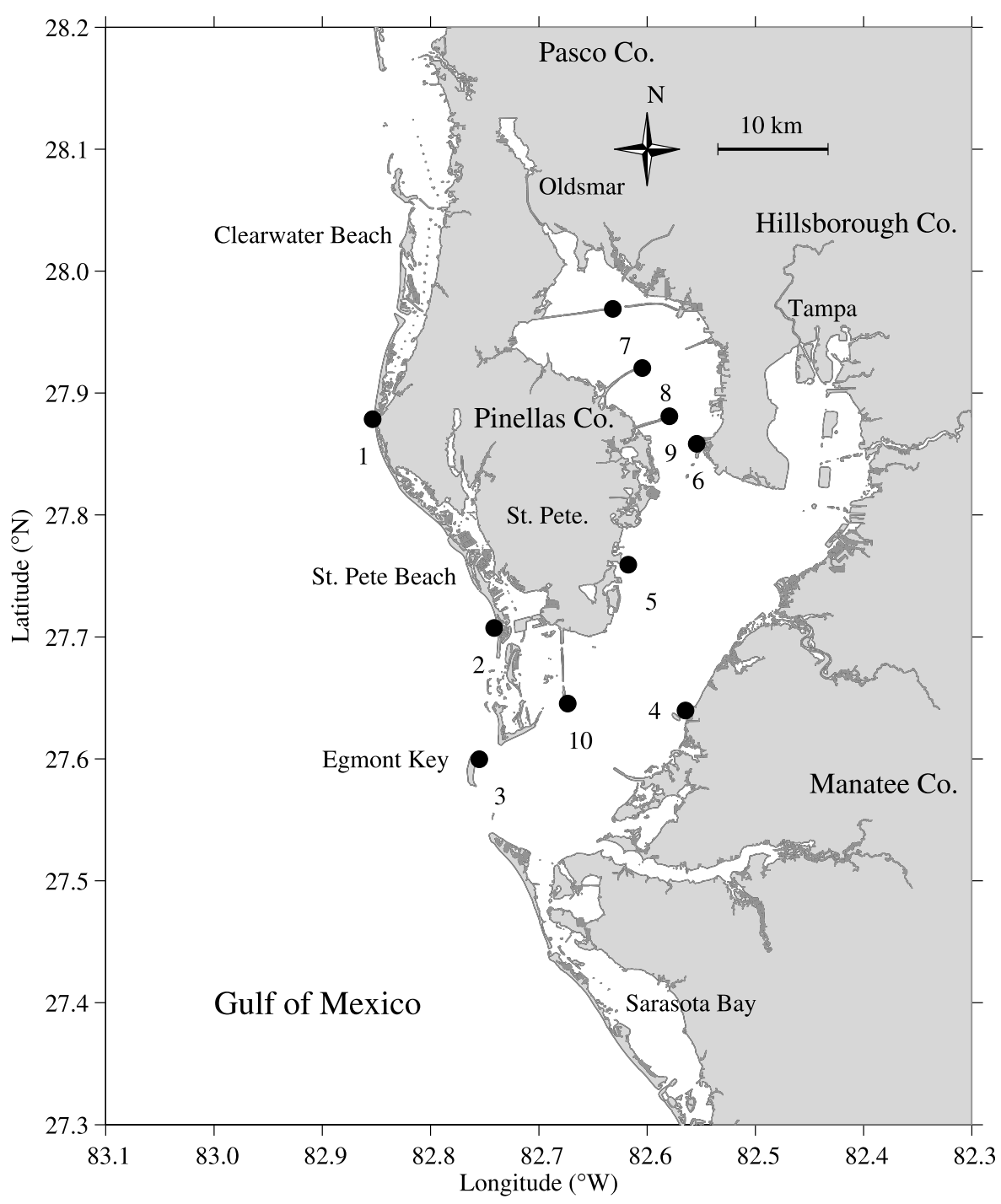

Figure 1. Tampa Bay and the adjacent West Florida shelf. Solid circles denote locations discussed in the text [from Weisberg and Zheng, 2008].

where $u, v$, and $\omega$ are the $x, y$, and $\sigma$ velocity components; $f$ is the Coriolis parameter; $K_{\mathrm{m}}$ is the vertical eddy viscosity; $\rho_{0}$ is the reference density; $\rho$ is the perturbation density; $D=$ $h+\eta$ is the total water depth, with $\eta$ and $h$ are the surface elevation and reference depth below mean sea level, respectively; $\eta_{\mathrm{a}}$ is the sea level displacement induced by the atmospheric pressure perturbation's inverted barometer effect; $F_{u}$ and $F_{v}$ are the horizontal momentum diffusion terms; and $F_{x}$ and $F_{y}$ are the wave-induced forces.

\subsection{Model Implementation}

[10] The coupled storm surge and wave model consists of two parts: a circulation model (using the unstructured, Finite Volume Coastal Ocean Model (FVCOM) of Chen et al. [2003]) and a wave model (using the unstructured version of SWAN [e.g., Zijlema, 2010]). The coupling is via the radiation stress as available in SWAN. Another unstructured wave model for future use is the FVCOM-Surface WAVE (SWAVE) [Qi et al., 2009].
[11] Our implementation extends previous analyses that were based on the circulation model without the added effects of waves [Weisberg and Zheng, 2008]. Here we apply the same unstructured FVCOM model domain, grid, atmospheric forcing functions (wind stress and air pressure), continental shelf geometry and bathymetry, and boundary conditions. The only difference is the inclusion of the waveinduced forces calculated from the unstructured SWAN model in which the wave spectrum is resolved at 42 logarithmically spaced frequencies between 0.04 and $2.00 \mathrm{~Hz}$, with an increment factor of 1.1, and at angular increments of $4^{\circ}$ between $0^{\circ}$ and $360^{\circ}$.

[12] One way coupling is employed in three steps. The first consists of an FVCOM run without wave-induced forces to derive an initial sea level field that is identical to the previous results [Weisberg and Zheng, 2008]. The SWAN model is then run using the sea level variations from FVCOM to derive the wave-induced forces. The third step is to rerun FVCOM with the added wave-induced forces. Further iterations are 

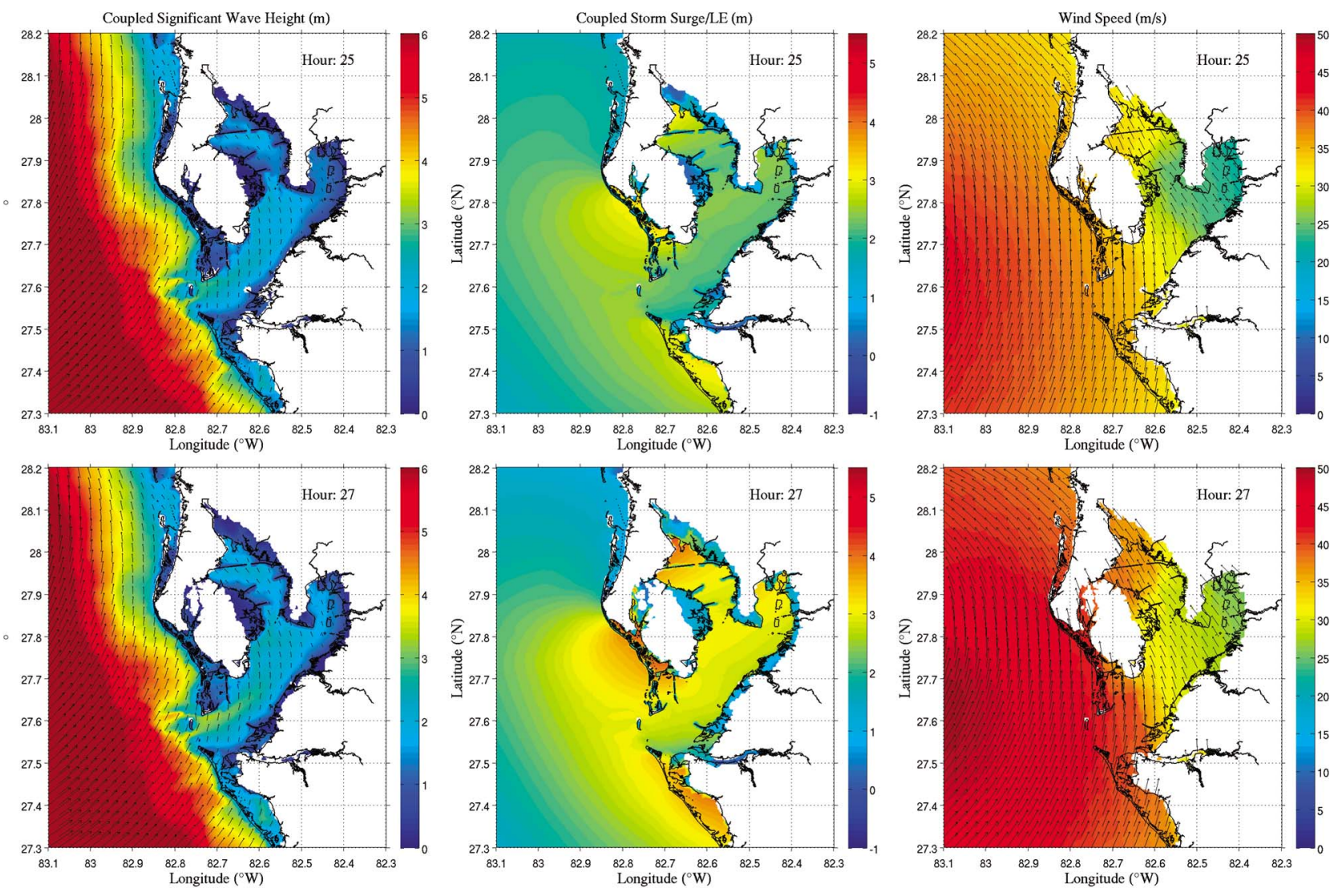

Figure 2a. Planar views of coupled model results for (left) significant wave height (height and direction vectors superimposed on height contours), (middle) storm surge relative to local (land or undisturbed sea level) elevation, and (right) the wind velocity vectors superimposed on wind speed contours. The top and bottom panels are for model hours 25 ( $5 \mathrm{~h}$ before landfall) and 27 ( $3 \mathrm{~h}$ before landfall), respectively.

deemed to be unnecessary because the incremental addition to the storm surge by the wave-induced forces, while tangible, are considerable less than the step 1 results. Nevertheless, wave-induced forces provide an incremental addition to hurricane storm surge, and the sea level variations by the storm surge itself greatly amplify the wave heights nearshore over what they are otherwise in the absence of storm surge. Thus, even a simplistic, incremental one-way coupling effectively illustrates the dual impacts of surge and waves on the coastal ocean environment.

\section{Results}

\subsection{Coupled Waves and Storm Surge}

[13] Weisberg and Zheng [2008] considered an Ivan-like hurricane with landfall at Indian Rocks Beach just north of the Tampa Bay entrance Figure 1 (Figure $2 b$, top right). The wind and pressure forcing functions properly represented the Ivan forcing fields except for their movement from west to east across the Tampa Bay region of Florida instead of their actual transit to Pensacola, FL. The coupled model results sampled at model hours 25 and 27,5 and $3 \mathrm{~h}$ before landfall, respectively, are provided in Figure 2a (top and bottom). From left to right, the three panels for each of the hours sampled are the wave vectors (significant wave height and direction of propagation) superimposed on contours of significant wave height, the storm surge height relative to land level (over inundated land) or mean sea level (over what would otherwise be water), and the wind vectors superimposed on wind speed contours. Similar presentations for model hours 30 (the time of landfall) and 31, respectively (when the storm is centered just east of Tampa Bay), are provided in Figure 2b (top and bottom).

\subsection{Effects of Wave-Induced Forces on Storm Surge}

[14] On the basis of this hypothetical, Ivan-like case study, storm surge results primarily from the action of the wind stress on the sea surface. Wave radiation stress adds to this, but only incrementally, as shown in Figures $3 \mathrm{a}$ and $3 \mathrm{~b}$. Figure 3a compares time series of surge elevation with and without [Weisberg and Zheng, 2008] waves sampled at several different locations (Figure 1) along the beaches, within the bay, and at certain critical points of infrastructure. Subtracting these two simulations (with and without waves) provides the incremental addition to surge caused by the wave radiation stress (Figure $3 b$ ), and this amounts to some $0.3-0.5 \mathrm{~m}$, which is about an order of magnitude less than the surge due to wind stress alone. Interestingly, the peak of the incremental surge by waves occurs in advance of the actual peak in the storm surge because the wave propagation speed exceeds the storm 

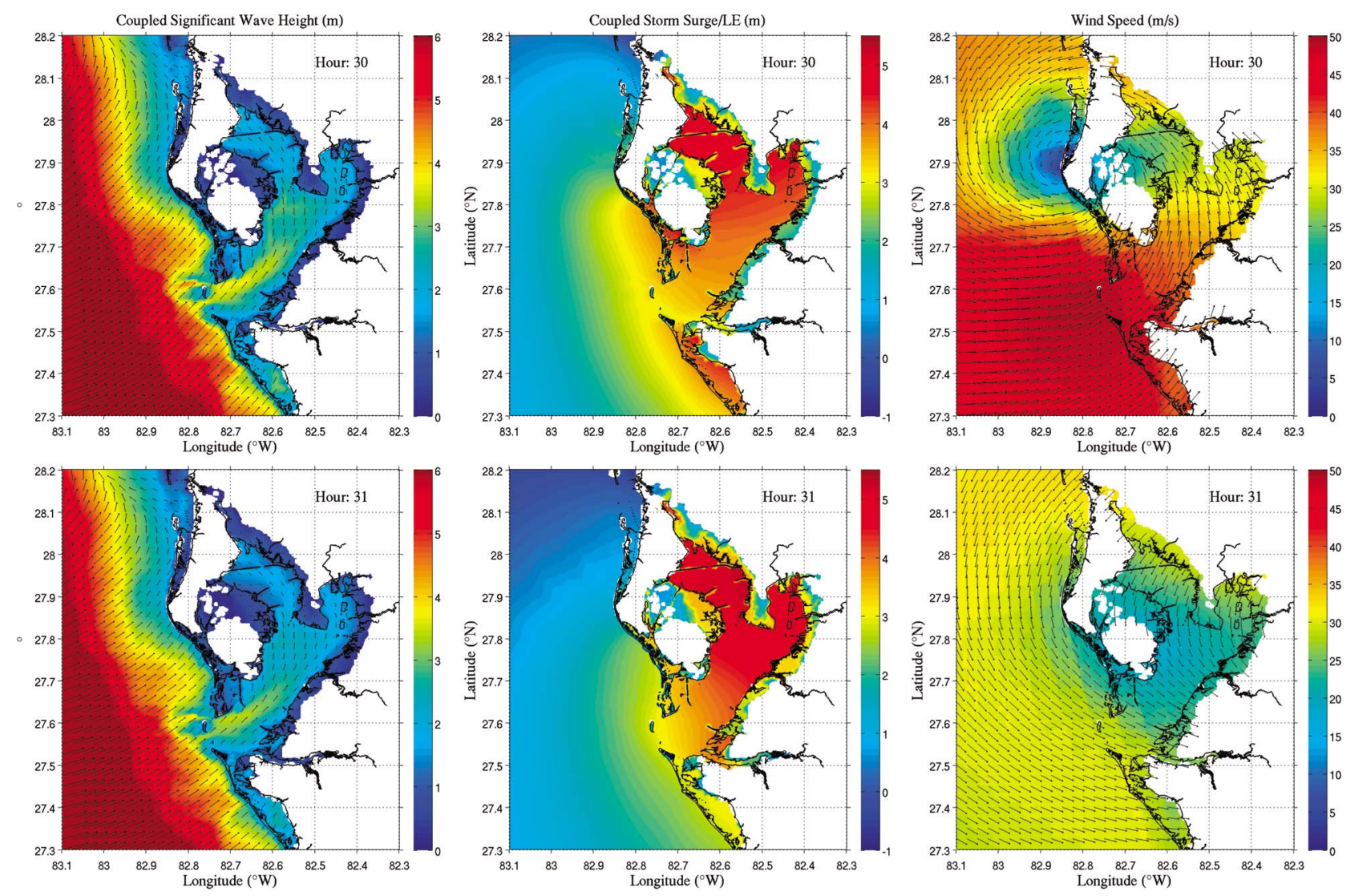

Figure 2b. Same as Figure 2a, except for sampling at model hours (top) 30 (at Indian Rocks Beach (IRB) landfall) and (bottom) 31 (1 h after landfall).

translation speed. The results obtained in this study are consistent with the study by Resio and Westerink [2008], where it is shown that for gently sloping continental shelf bathymetry the relative contribution may only be a few percent, whereas for steeply sloping bathymetry the surge by wave radiation stress may be much larger.

[15] Spatial patterns of the incremental surge height differences along with the wave-induced forces that are responsible for these incremental differences are given for model hours 25 (Figure 4, top) and 30 (Figure 4, bottom). The left-hand panels are the wave radiation stress gradients (wave-induced forces per unit area acting on the sea surface along with the wind stresses), and the right-hand panels are the incremental surge heights due to these wave-induced forces. The radiation stress gradients are largest where the wave momentum is changing most rapidly in space. Gently sloping bathymetry allows the radiation stress variation to be spread over a larger distance, reducing the gradient and the incremental wave effect on surge, and conversely. Thus, a steeper bathymetric slope will cause larger incremental surge and larger waves, although steeper bathymetry will also lessen the surge height by wind stress alone because the surface slope is inversely proportional to water depth. Timing as before is again important. Along the beaches, we see that the incremental surge is largest early in the inundation sequence as large waves begin to approach the shoreline. Although this still only amounts to some $0.3 \mathrm{~m}$, it may be large enough in the presence of waves to begin damaging beachfront houses well in advance of hurricane landfall.

\subsection{Storm Surge Effects on Waves}

[16] The flip side to the effects of waves on storm surge is the effects of storm surge on waves. By running the wave model with and without storm surge, time series of the model-simulated significant wave height (SWH) are shown in Figure 5a, sampled at the same 10 locations (Figure 1) as in Figure 3a (for surge height difference). We see that the SWH is substantially different with and without storm surge at most of these locations, with the surge elevation increase resulting in about a $1.0-1.5 \mathrm{~m}$ increase in $\mathrm{SWH}$ and hence perhaps as much as a $2-3 \mathrm{~m}$ increase in maximum wave height.

[17] Spatial distributions of these differences sampled at model simulation hours 27 ( $3 \mathrm{~h}$ before landfall) and 30 (landfall) are show in Figure 6. From these we see that the SWH differences increase with increasing surge height (Figures 2a and 2b). Given that Tampa Bay is generally shallow (with an area-weighted mean depth of only about $4 \mathrm{~m}$ ) the storm surge, by adding as much as $5 \mathrm{~m}$ to the water depth inside the bay, greatly increases the 

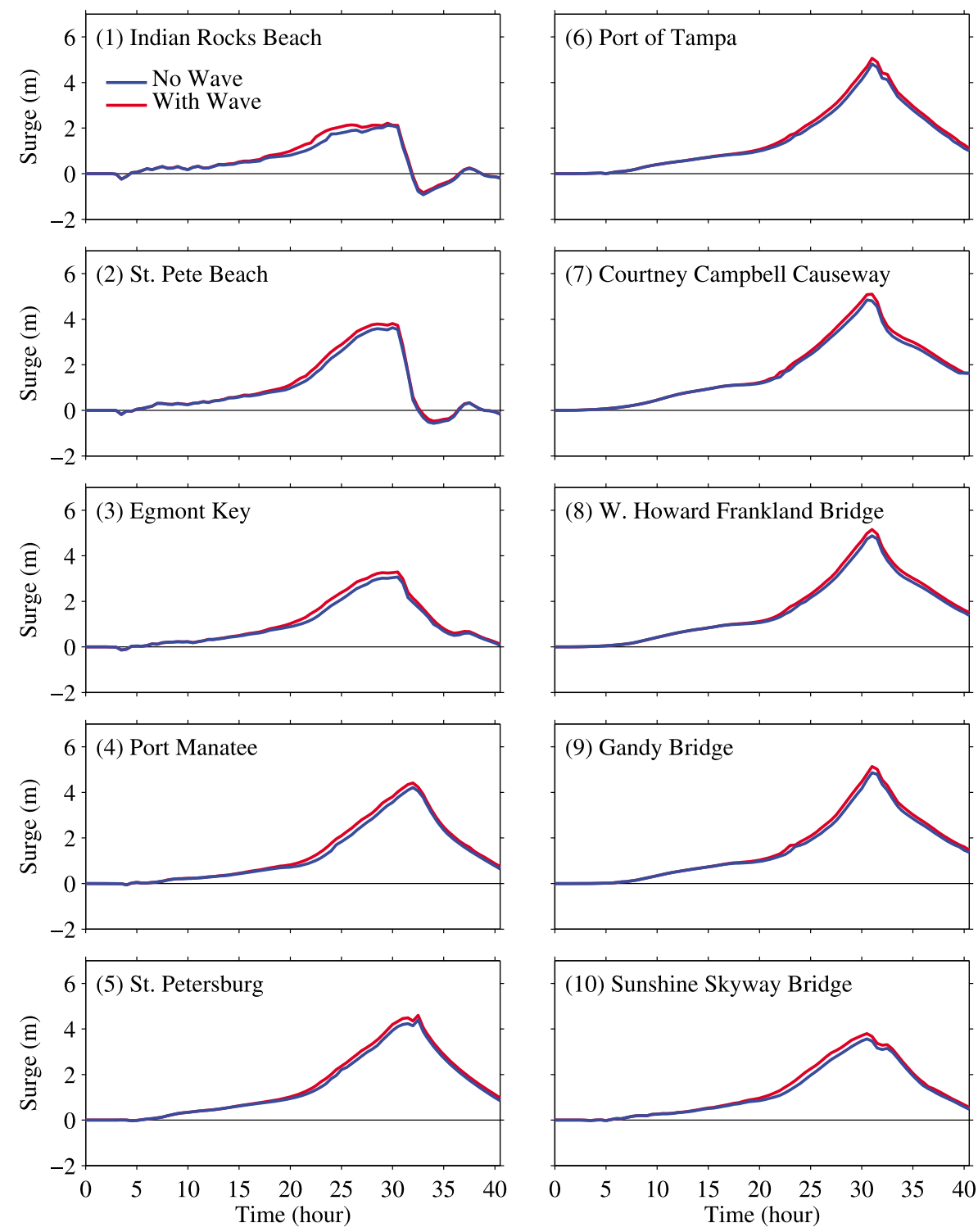

Figure 3a. Time series of the model-simulated surge sampled at (counterclockwise from the top left): Indian Rocks Beach, St. Pete Beach, Egmont Key, Port Manatee, St. Petersburg, the Port of Tampa, the Courtney Campbell Causeway, the Howard Frankland Bridge, the Gandy Bridge, and the Sunshine Skyway Bridge. The blue and red lines denote the model results without and with wave-induced force effects, respectively.

SWH within the bay and along the Gulf of Mexico beachfront. The relationship between the SWH difference and the surge elevation is clearly seen when comparing the SWH increases (Figure 5b) Figure 6 with the surge heights (Figure 3a).

[18] In proportion, we find that the enhancements to the SWH by storm surge are much larger than enhancements to the storm surge by the wave-induced forces. This is because the Tampa Bay region abuts a gently sloping continental shelf, allowing wind stress to far outweigh radiation stress in generating storm surge [Resio and Westerink, 2008]. However, given that the forces by waves on structures are potentially so enormous (for instance, the destruction of many reinforced concrete bridge spans during Hurricanes
Ivan and Katrina), the increase of SWH by the increased water depth (due to the largely wind stress-induced storm surge) is perhaps the most important aspect found in this coupling of storm surge and wave models.

\section{Hypothetical Experiment Reliability}

[19] Our application of a coupled, storm surge and wave model to a hypothetical event for Tampa Bay follows from our previous application for surge alone in which Weisberg and Zheng [2008] concluded that (1) Tampa Bay is as susceptible to damage and destruction by water-related hurricane impacts as was coastal Mississippi for Katrina and (2) storm surge models using a 2-D formulation can significantly 

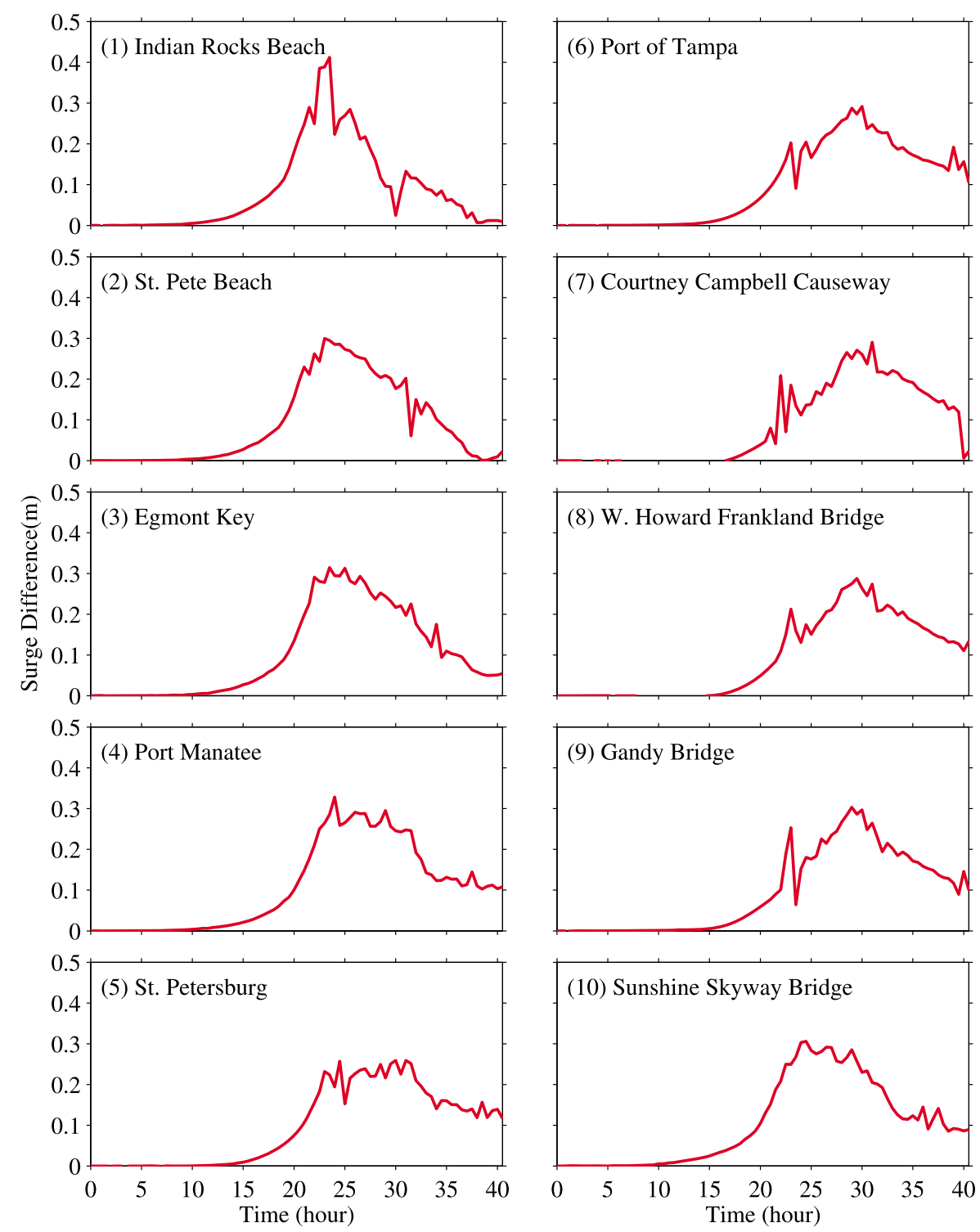

Figure 3b. Time series of surge differences without and with wave-induced forces (i.e., the differences between the red and blue lines of Figure 3a.)

underestimate storm surge when compared with a 3-D formulation, all else being equal. Because of the first conclusion we hope that we never have actual data to compare with the hypothetical results reported here. Nevertheless, the physics are readily understandable and testable (as performed in the study by Weisberg and Zheng [2008] in support of their second conclusion).

[20] Both of our findings have support in either observations or scale analyses. The SWAN model using Ivan winds shows a maximum in SWH of about $20 \mathrm{~m}$ in deep water. Actual Hurricane Ivan observations showed maximum SWH of $17.9 \mathrm{~m}$ roughly $75 \mathrm{~km}$ from the hurricane eye, which when extrapolated suggested a maximum SWH of $21 \mathrm{~m}$ [Wang et al., 2005], consistent with our SWAN model results.
[21] By scale analyses we can also test the veracity of the modeled wave-induced force setup. Considering an approximate balance between the pressure gradient force by an incremental surface slope setup over a horizontal length $L$ and a wave-induced force acting uniformly across a water column of depth $h$, we can estimate the incremental surge elevation by wave radiation stress. Thus, $\Delta \zeta=L \tau_{w} / \rho g h$, where $\tau_{\mathrm{w}}$ is the average wave-induced force per unit area, $h$ is the mean water depth, $\rho$ is the water density, and $g$ is the gravitational acceleration. Using $L=60 \mathrm{~km}, h=20 \mathrm{~m}$, and $\tau_{\mathrm{w}}=1 \mathrm{~N} / \mathrm{m}^{2}$, we estimate $\Delta \zeta \approx 0.3 \mathrm{~m}$, consistent with Figure 4. Finally, our results for the incremental surge by waves is similar to that found by the IPET (Intergovernmental Performance Evaluation Team) for Hurricane 

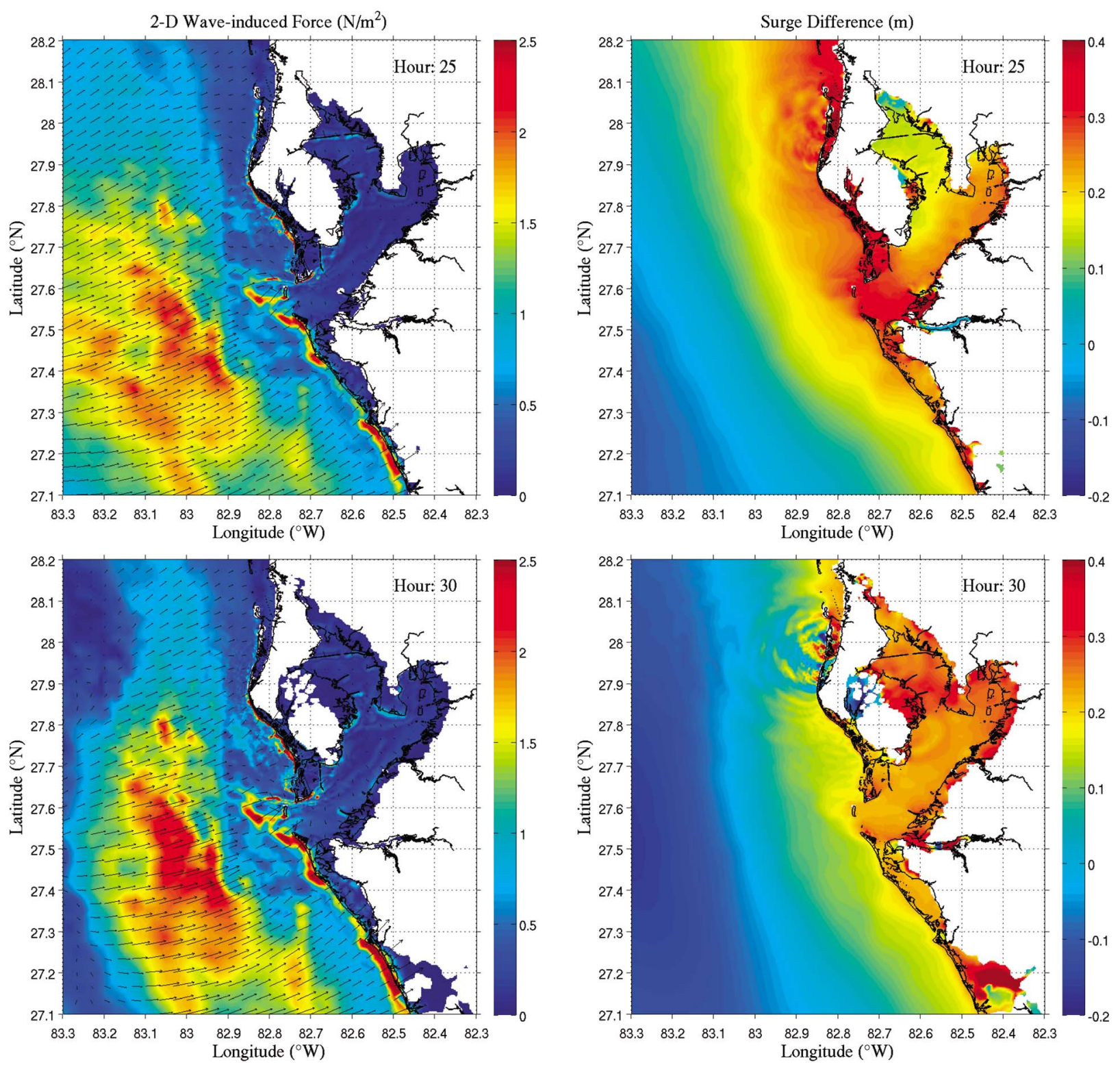

Figure 4. Planar views of (left) the 2-D wave-induced forces per unit area and (right) the surge differences with and without these sampled at model hours (top) 25 and (bottom) 30.

Katrina (https://ipet.wes.army.mil/) using a similar wave radiation stress formulation [Luettich and Westerink, 1999].

\section{Discussion}

[22] Discussing the joint evolution of waves and surge over such a large time span is important because of the dynamical differences between waves and surge. With hurricane-generated waves traveling faster than the hurricane itself, the destructive potential of the waves precedes that of either the winds or the surge. Thus, by hour $25(5 \mathrm{~h}$ before landfall) and with the storm center still some $100 \mathrm{~km}$ west of Tampa Bay, the significant wave heights along the coastline, and even inside the bay, already exceed 1-2 m (Figure 2a, top left). This precursor effect is worsened by the fact that wave packets may have individual waves of 1.9 times the significant wave height [e.g., Bea, 1974], which is consistent with wave measurements obtained during Hurricane Ivan [Wang et al., 2005]. Had this hypothetical event actually occurred, such significant wave heights in advance of the storm, when coupled with the onset of inundation, would have been sufficient to initiate large-scale damage within the Tampa Bay region prior to the onset of hurricane strength winds.

[23] By hour 27 ( $3 \mathrm{~h}$ before landfall) and with the storm center still some $60 \mathrm{~km}$ west of landfall, both the inundation and the significant wave heights would be sufficiently high to begin causing massive damage to buildings if situated at low elevation and with open water exposure, despite the wind speeds within the bay being less than those of hurricane 

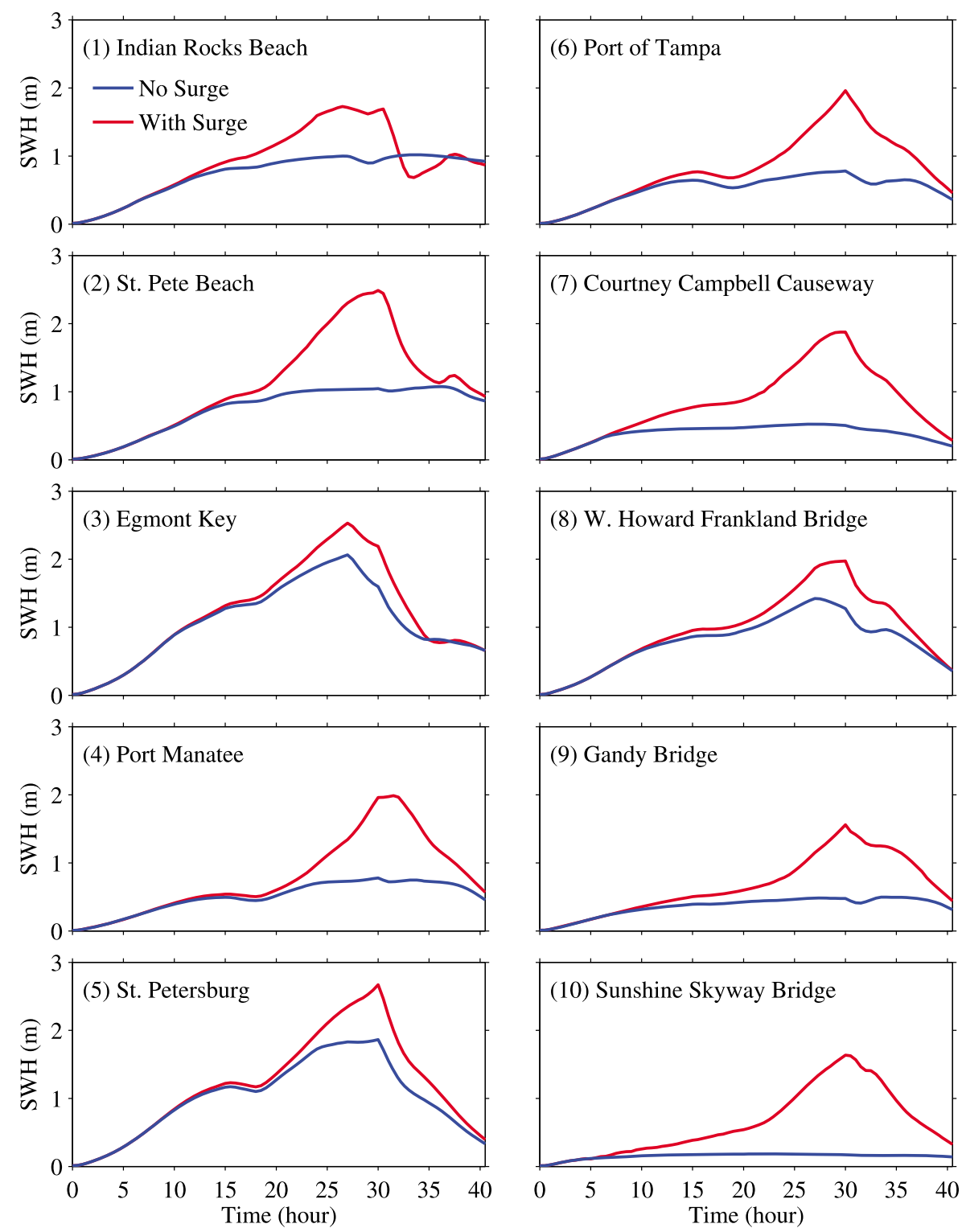

Figure 5a. Same as Figure 3a but for the significant wave height (SWH) time series sampled at these locations.

strength. Particularly, hard hit would be the northeast section of St. Petersburg and the northern sections of Old Tampa Bay, including the bridge spans that link St. Petersburg with Tampa (the Courtney Campbell Causeway, the Howard Frankland Bridge, and the Gandy Bridge).

[24] For inundation of land by storm surge, coupled with the destructive effects of waves, the situation worsens at the moment of hurricane landfall (hour 30). Note that despite the wind speeds remaining less than those of hurricane strength over the northern half of the bay, the inundation continues to increase along with the significant wave heights, and this situation worsens into hour 31 with the storm center passing to the east of Tampa Bay. Hence, it is not simply the wind speed (Saffir-Simpson scale category of the storm) that matters rather it is the complex, timeintegrated and space-integrated effects of the surge and waves. Essentially, the entire periphery of Tampa Bay with low elevation and open water exposure is as susceptible to damage and destruction as was the Mississippi coastline during Hurricane Katrina. This would even be the case for the eastern shore of Tampa Bay after the storm translates beyond Tampa Bay and the wind speeds begin to abate because the bay would already be filled with storm surge water and waves, and these would shift with the wind direction to strike the eastern shore where the inundation relative to the land elevation reaches its maximum value.

[25] As regards infrastructure, it is likely that the wave forces acting vertically beneath bridge spans [e.g., Patarapanich, 1984] would destroy spans of the Courtney Campbell Causeway, the Howard Frankland Bridge, and the Gandy Bridge wherever the surge is high enough for the waves to reach the underside of these bridge spans (similar to what happened during the actual Ivan encounter with Pensacola and also with the Katrina encounters at Bay St. Louis and Biloxi, MS). 

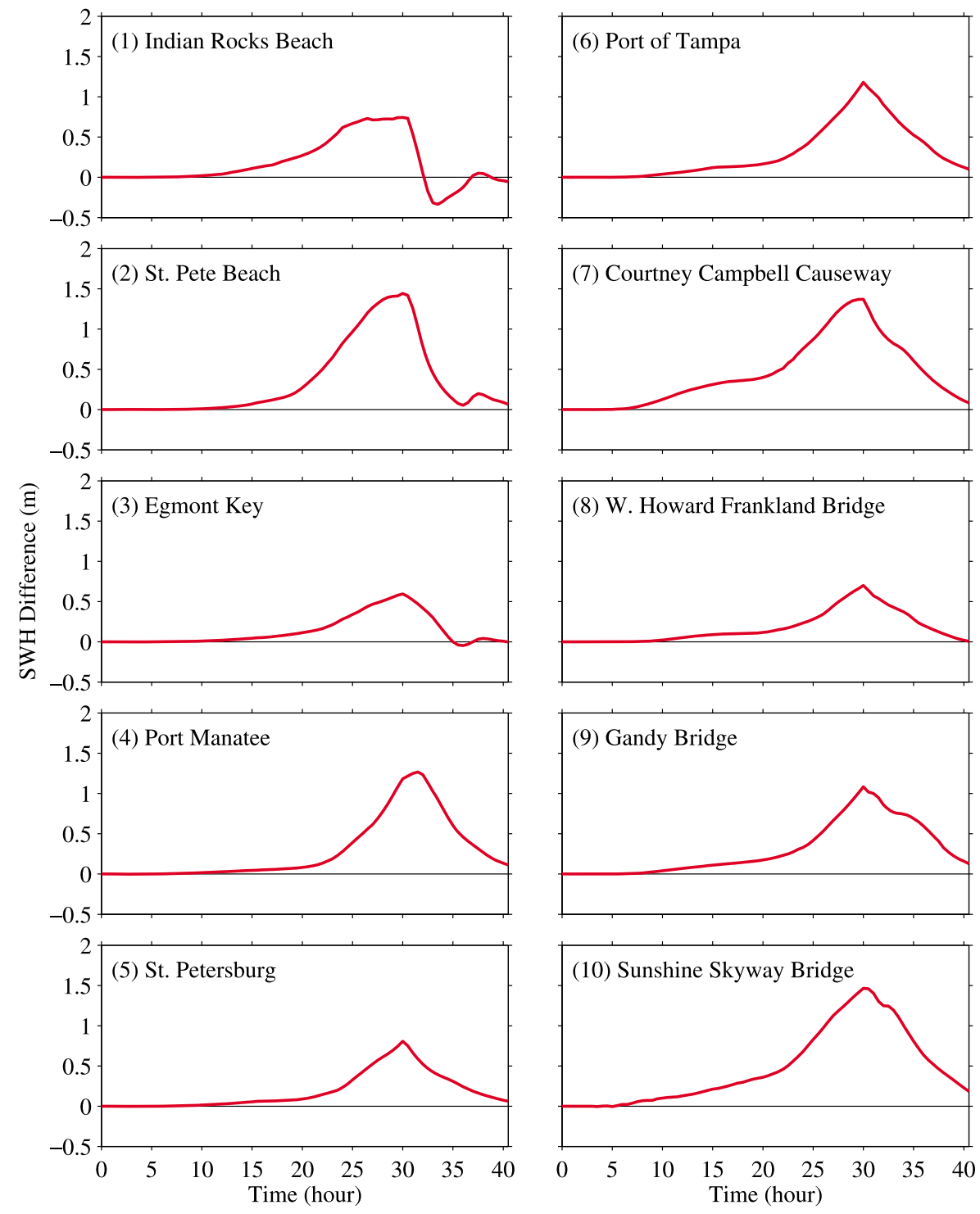

Figure 5b. Time series of the differences in the SWH (i.e., the differences between the red and blue lines of Figure 5a).

Similarly, McDill Air Force Base and Tampa International Airport would be damaged along with Tampa General Hospital, just to mention a few critical areas of infrastructure. In view of the real damage by Katrina to New Orleans and the entire coast of Mississippi, such projected impacts must be taken seriously. Surge is what raises the water level, but it is the waves that apply the most destructive of the water-related forces, even if the wind speeds alone are less than critically damaging. Only through coupled wave and surge modeling can these combined effects be recognized.

\section{Summary and Conclusions}

[26] By coupling unstructured grid, wave and coastal ocean circulation models (SWAN and FVCOM, respectively), we considered the role of wave-induced forces on hurricane storm surge and the role of storm surge on the nearshore wavefield. The experimental milieu was that of a hypothetical Ivan-like hurricane, making landfall just north of Tampa Bay, FL. Two principal findings are as follows. First, the effects of wave-induced forces on storm surge are incremental to the surge by wind stress alone, consistent with the relative magnitudes of the wave and wind stresses. Second, the effects of increased water depth by surge on the nearshore wavefield is substantial, consistent with nearshore (and inundated land) water depths being largely increased by storm surge. Because of these two findings, the simplest, one-way coupling between surge and wave models is effective.

[27] Our conclusions are additive to those of Weisberg and Zheng [2008]. Of concern in a general sense beyond Tampa Bay and dependent upon shelf width and local geometry are (1) hurricane storm surge when estimated by 3-D models may be significantly larger than when estimated 

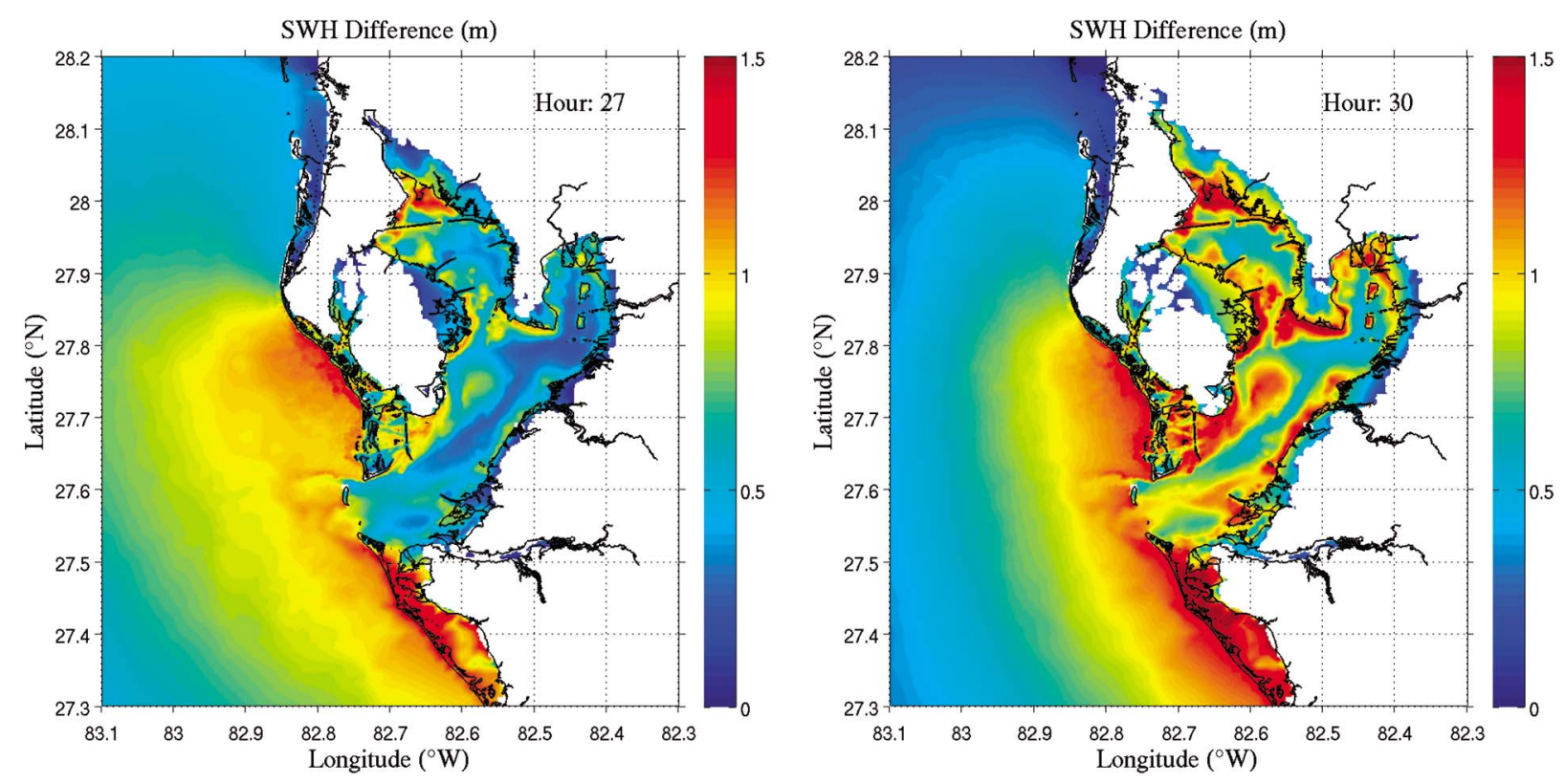

Figure 6. Planar views of the SWH difference sampled at model hours (left) 27 (3 h before landfall) and (right) 30 (at IRB landfall).

by $2-\mathrm{D}$ models, all else being the same; (2) waves incrementally add to storm surge, whereas (3) storm surge substantially impacts the nearshore wavefield; and (4) the wave effects begin in advance of the storm surge effects nearshore (without waves) because waves can propagate faster than storms generally translate. In summary, storm surge modeling as applied by agencies responsible for public safety awareness and insurance underwriting remains an evolving problem. Important improvements are possible given the advances in both wave and coastal ocean circulation models and the computer hardware necessary to run these.

[28] Acknowledgments. Support was by the Office of Naval Research grant N00014-05-1-0483, the National Oceanic and Atmospheric Administration grant NA07NOS4730211, and the Florida State University subcontract R01279. Special thanks are offered to Marcel Zijlema, Delft University of Technology, for sharing expertise with the unstructured SWAN model, and to Changsheng Chen, University of Massachusetts, Dartmouth, for his continued FVCOM guidance.

\section{References}

Bea, R. G. (1974), Proceedings of the Sixth Offshore Technology Conference, Houston, TX, 76 to 8 May 1974, pp. 791-810, Offshore Technology Conference, Dallas, Tex.

Bowen, A. J., D. L. Inman, and V. P. Simmons (1968), Wave "set-down" and setup, J. Geophys. Res., 73(8), 2569-2577, doi:10.1029/JB073i008p02569.

Chen, C. S., H. D. Liu, and R. C. Beardsley (2003), An unstructured, finitevolume, three-dimensional, primitive equation ocean model: Application to coastal ocean and estuaries, J. Atmos. Oceanic Technol., 20, 159-186.

Jelesnianski, C. P., J. Chen, and W. A. Shaffer (1992), SLOSH: Sea, lake, and overland surges from hurricanes, NOAA Tech. Report NWS 48, 77 pp., National Weather Service, NOAA, Silver Spring, Md.

Large, W. G., and S. Pond (1981), Open ocean momentum fluxes in moderate to strong winds, J. Phys. Oceanogr., 11, 324-336.

Longuet-Higgins, M. S., and R. W. Stewart (1964), Radiation stress in water waves: A physical discussion with applications, Deep Sea Res. $11,529-562$.

Luettich, R. A., and J. J. Westerink (1999), Implementation of the wave radiation stress gradient as a forcing for the ADCIRC hydrodynamic model: Upgrades and documentation for ADCIRC version 34.12, contractors report, 9 pp., Dep. of the Army, US Army Corps of Engineers, Waterways Experiment Station, Vicksburg, Miss.

Mastenbroek, C., G. Burgers, and P. Janssen (1993), The dynamical coupling of a wave model and a storm surge model through the atmospheric boundary layer, J. Phys. Oceanogr., 23, 1856-1866.

Mellor, G. L., M. A. Donelan, and L. Y. Oey (2008), A surface wave model for coupling with numerical ocean circulation models, J. Atmos. Oceanic Technol., 25, 1785-1807.

Patarapanich, M. (1984), Forces and moment on a horizontal plate due to wave scattering, Coastal Eng., 8, 279-301.

Phillips, O. M. (1977), The Dynamics of Upper Ocean, 336 pp., Cambridge Univ. Press, New York.

Qi, J., C. Chen, R. C. Beardsley, W. Perrie, G. W. Cowles, and Z. Lai (2009), An unstructured-grid finite-volume surface wave model (FVCOM-SWAVE): Implementation, validations and applications, Ocean Modell., 28, 153-166.

Resio, D. T., and J. J. Westerink (2008), Modeling the physics of storm surges, Phys. Today, 33-38.

Sallenger, A. H., H. F. Stockdon, L. Fauver, M. Hansen, D. Thompson, C. W. Wright, and J. Lillycrop (2006), Hurricane 2004: An overview of their characteristics and coastal change, Estuaries, 29, 880-888.

Wang, D. W., D. A. Mitchell, W. J. Teague, E. Jarosz, and M. S. Hulbert (2005), Extreme waves under Hurricane Ivan, Science, 309, 896.

Weisberg, R. H., and L. Zheng (2008), Hurricane storm surge simulations comparing three-dimensional with two-dimensional formulations based on an Ivan-like storm over the Tampa Bay, Florida region, J. Geophys. Res., 113, C12001, doi:10.1029/2008JC005115.

Westerink, J. J., and R. A. Luettich (1991), Tide and storm surge prediction in the Gulf of Mexico using model ADCIRC-2D, report, 112 pp., U. S. Army Engineers Waterways Experiment Station, Vicksburg, Miss

Xie, L., L. J. Pietrafesa, and K. Wu (2003), A numerical study of wavecurrent interaction through surface and bottom stresses: Coastal ocean response to Hurricane Fran of 1996, J. Geophys. Res., 108(C2), 3049, doi:10.1029/2001JC001078.

Zijlema, M. (2010), Computation of wind-wave spectra in coastal waters with SWAN on unstructured grids, Coastal Eng., 57(3), 267-277, doi:1016/j.coastaleng.2009.10.011.

Y. Huang, R. H. Weisberg, and L. Zheng, College of Marine Science, University of South Florida, 140 Seventh Ave. S., St. Petersburg, FL 33701-5016, USA. (huang_17@hotmail.com) 